\title{
Peaks and Valleys: \\ A Two-year Study of Student Leadership Capacity Associated with Campus Involvement
}

\author{
David M. Rosch \\ Associate Professor \\ Agricultural Education \\ University of Illinois at Urbana-Champaign \\ Jasmine D. Collins \\ Assistant Professor \\ Agricultural Education \\ University of Illinois at Urbana-Champaign
}

\begin{abstract}
This study followed 134 university students within a national sample for one or two years, from their initial participation in a LeaderShape Institute session. We examined the shape of their trajectories of leadership growth over this course of time, with particular focus on development long after the session had ended. We also investigated the degree to which additional formal leadership development opportunities statistically predicted leadership development. Results indicated a typical non-linear shape to development and suggested that most formal experiences, as a whole, possess little association with leadership growth when controlling for other experiences associated with leadership development in students.
\end{abstract}

\section{Introduction}

A distinct need exists to examine the long-term developmental trajectories of young adults in regards to their growth as emerging leaders, particularly within the context of formal educational settings. While post-secondary institutions have long labeled themselves as the developers of future societal leaders (Dugan \& Komives, 2007), the field of research focused on how universities accomplish this mission is largely untapped (Dugan, 2011). Unequivocally offering a challenge to researchers and leadership educators alike, Owen (2012) described the field of student leadership development as facing an "awkward adolescent stage" (p. 20) where the programs designed to support student growth should be better matched with data-driven practices and empirical research.

Formal leadership learning opportunities exist on most university campuses, but rigorous national datasets to describe their effects or indicate their success have been rare. A common assessment or research design is a simple two-stage repeated-measures study, where program participants complete a pre-test prior to their experience and a post-test immediately after. However, these studies have long been recognized for their lack of validity, based on a strong response-shift bias (Howard \& Dailey, 1979) and their lack of opportunity for students to apply their learning in any meaningful way to better self-assess the outcomes of their participation (Rosch \& Schwartz, 2009). A tiny number of rigorous national datasets designed to increase the 
rigor and validity of leadership education research do exist, most notably the Multi-Institutional Study of Leadership (MSL; Dugan \& Komives, 2007). The MSL is cross-sectional in nature, though, eliminating the possibility of ascertaining growth across a practically significant timespan within individual students, thus weakening the ability of researchers to better understand the shape of student leadership development over time. This study was designed to investigate this frustrating gap in understanding how students grow in their capacity to lead over time and as a result of participating in formal university learning opportunities.

Campus-based Effects on Student Leadership Growth. While popular media continue to discuss the idea of whether leaders are "born or made," generations of research on the effects of participating in formal interventions designed for leadership development indicate the potential for individuals to grow in capacity over time (Day \& Sin, 2011). Moreover, research that examines the effects of participating in postsecondary campus experiences on student leadership development has greatly accelerated in recent years (Komives, Dugan, Owen, Slack, \& Wagner, 2011). Contemporary empirical research has suggested, for example, that university students can augment their capacity to lead through participating in formal academic leadership courses (Keating, Rosch, \& Burgoon, 2014), student organization participation (Dugan, 2008; Harper \& Quaye, 2007), co-curricular leadership programs (Dugan et al., 2011; Dugan, Kodama, Correia, \& Howes, 2013), mentoring programs (Campbell, Smith, Dugan, \& Komives, 2012; Rosch \& Stephens, 2017), and community service programs (Soria, Nobbe, \& Fink, 2013).

However, the vast majority of these empirical studies are essentially analyses of correlations, where investigators compare quantitative leadership scale scores of students who participate in leadership initiatives with those who do not. While helpful, these results are often presumed to show that such participation is what led to an increase in scores, when it is just as possible that students who choose to participate possessed higher scores related to personal or unrelated environmental predictors (Day, 2001). In addition, most college impact studies, especially those that involve multiple institutions or are conducted on large, decentralized campuses, suffer from a lack of control (Dugan, 2011); for example, a "leadership program" may presume certain curricula on one campus and very different curricula on another (Rosch \& Kuzel, 2010). Given the lack of clarity regarding the actual effects of participation, studies that follow individual students over time are necessary.

Assessing Longitudinal Leadership Development. There are several reasons that the overwhelming bulk of leadership development research has focused on short-term data collection and assessment only on immediate results. Longitudinal efforts to collect intra-individual data through repeated waves of data collection over time are often expensive and typically result in significant participant mortality (Posner, 2009). Much more typically, cross-sequential studies have been conducted, where data is collected from participants only once. Within a crosssequential design, conclusions can be drawn about participant growth by comparing participants who are older or more experienced in variables of interest with those who are younger or less experienced (Pearson, 2009). Despite being cheaper and easier to conduct, conclusions about growth over time within cross-sequential studies are based on presumptions that research participants start at identical places of development and progress similarly over time. Unfortunately, most research on adolescents and young adults indicate that such uniformity is not often the case (Steinberg \& Morris, 2001). Research shows that adolescents, whether 
measured individually or as part of various social identity groups, come to their university campus already significantly differing in their degree of leadership capacity (Rosch, Ogolsky, \& Stephens, 2017). Moreover, while repeated measures designs that include only a pre-test and post-test conducted in the relatively immediate aftermath of an intervention are popular, they do not allow for participants to more rigorously assess the true nature of their development possible only after applying newly-learned material in their own contexts.

Recent calls have been made for more longitudinal research that examines the impact of student participation in university settings (Seifert, Bowman, Wolniak, Rockenbach, \& Mayhew, 2017). A single-campus study showed encouraging gains in students when measured during their first year in postsecondary education and again as seniors (Posner, 2009), but the authors did not conduct any inferential statistics, having only compared mean scores by eye. Without including $p$ statistics or effect sizes, it was impossible to determine the rigor of any conclusions drawn. A national study recently revealed longitudinal gains as a result of participating in a co-curricular program (Rosch et al., 2017), but collected data only within a four-month timeframe. Other studies examining positive gains in leadership courses (Buschlen \& Johnson, 2014; Keating et al., 2014) utilized similarly short data collection periods. In addition, other studies that examine gains in leadership capacity over time, utilizing a months-long collection period, show decreases in capacity over time (Day \& Sin, 2011; Rosch, 2015). Day and Sin (2011) attribute these disappointing results to the unexpected nature of challenges students face when initially practicing leadership in uncontrolled environments after receiving structured training. A distinct needs exists to measure the shape of students' leadership development trajectories over the course of years to more rigorously understand how campus-based factors (e.g. formal leadership training, student organization involvement, leadership courses) effect such development. To engage in such study, we must first explain how we employed a particular conceptual framework of "leadership development."

A Conceptual Framework of Leadership Development. In recent years, the development of knowledge and skills associated with postindustrial leadership (Rost, 1993) has received increased attention from postsecondary institutions, national educational organizations, accrediting agencies, and employers (Astin \& Astin, 2000; Gurin, Dey, Hurtado, \& Gurin, 2002; Komives et al., 2011). Unlike industrial or managerial conceptualizations of leadership which position leaders atop a hierarchical structure in an effort to maintain the status quo, contemporary, or postindustrial, leaders are called to behave in collaborative ways in an effort to enact intentional change (Northouse, 2015; Rost, 1993). In line with this paradigm, skills such as collaborative problem solving, communication, social and intercultural awareness and competence, are often cited as critical learning outcomes for today's students (Association of American Colleges \& Universities, 2008; Astin \& Astin, 2000; Council for the Advancement of Standards in Higher Education, 2009; Hurtado, 2007; National Association of Colleges and Employers, 2013).

The Ready, Willing, and Able conceptual model of leadership capacity (Keating, Rosch, \& Burgoon, 2014; see Figure 1) depicts three interconnected components of contemporary leadership that serve to bolster one another when operating together. That is, in order for student leaders to maximize their capacity, they must simultaneously develop in the areas of leadership self-efficacy, motivation, and skill. A student who possesses the requisite skill to lead, but does 
not believe that his or her efforts will lead to success, for example, may eschew opportunities to engage in leadership-oriented behaviors.

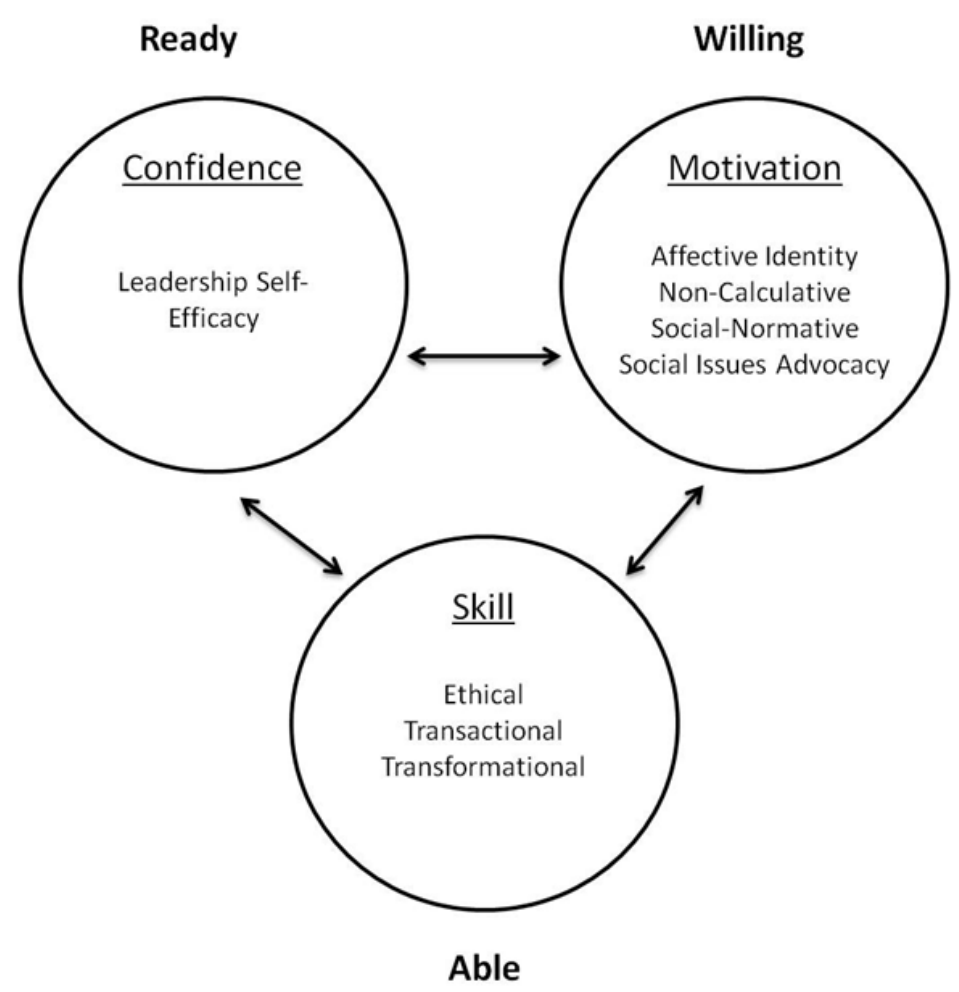

Figure 1. The "Ready, Willing, and Able" Conceptual Model of Leadership Capacity (Keating et al., 2014)

Within this model, "Ready" refers to one's capacity for leadership self-efficacy, or the confidence that one's leadership-oriented behaviors will lead to success (Hannah, Avolio, Luthans, \& Harms, 2008; Murphy, 1992). "Willing" is defined as the capacity for motivation to engage in leadership behaviors. Lastly, to be "Able" is to possess the capacity to exercise Transformational, Transactional and Ethical leadership skills. Transformational leadership skill is defined as the capacity to build authentic relationships, adhere to broad ethical standards, and create sustainable change while working with others within a group (Burns, 1978). Transactional leadership skill refers to the ability to create a motivating system of work through a system of structure and rewards within a team to achieve goals (Bass, 1998). Ethical leadership skill refers to the capacity to lead in ways that adhere to societal and organizational standards (Brown, Treviño, \& Harrison, 2005). The Ready, Willing, Able (Keating et al., 2014) model has been used in several studies to assess the leadership development of students in higher education settings (Collins et al., 2017; Rosch et al., 2016; Rosch, Stephens, et al., 2015). 


\section{Research Purpose}

Our research aim was to conduct a longitudinal analysis of student leadership capacity change over the course of one to two years on students who participate in formal leadership development opportunities and a variety of other campus factors previously associated with leadership growth. Therefore, we possessed the following research questions:

1. What is the shape of the leadership skill, motivation to lead, and leadership selfefficacy-related developmental trajectories of students who participate in these formal and informal opportunities?

2. Long after participating in a formal leadership learning intervention, do students retain and potentially continue to grow in their leadership capacity, and is growth associated with involvement in other interventions on campus?

\section{Method}

Student participants of the six-day LeaderShape Institute during data collection years Academic Year 2014 (AY14, August 2013- July 2014) and Academic Year 2015 (AY15, August 2014 - July 2015) served as the population for the present study. Survey data were collected in four phases. Phase 1, the pre-test, was administered prior to participation in the Institute. Phase 2, the post-test, was administered directly after the completion of the sixth day of the Institute. Participants received an electronic Phase 3 follow-up survey four months after the conclusion of their Institute session. The Phase 4 survey was sent electronically to participants in the late spring of 2016. This marked the conclusion of the data collection period, and thus served as a good time for a final survey of all research participants as necessary to connect initial durable gains with longitudinal gains assessed years later. Due to this census-style approach, participants received the Phase 4 instrument one or two years after the conclusion of their Institute session.

Data Collection Site. LeaderShape, Inc. is a not-for-profit organization that partners with businesses, community organizations, and university campuses - mostly within the United States - to offer formal leadership programming focused on personal growth and community impact (leadershape.org). LeaderShape's longest-standing program, the immersive 6-day Institute, is designed to challenge college student participants to "lead with integrity while working towards a vision grounded in their deepest values" (leadershape.org). Over the course of the six continuous days, Institute participants reside in an off-campus retreat site, actively engaging in both large group ( 40 - 60 participants lead by a team of two co-facilitators) and smaller cluster group (6 - 10 participants lead by one facilitator) activities and discussions. Students are recruited for participation in campus-hosted Institute sessions through an application process that is unique to each campus. Students interested in participating in a national session (comprised of students from national and international partner institutions) may apply directly through the LeaderShape website (leadershape.org). Over 4,000 students participate in Institute sessions annually.

Sample. LeaderShape, Inc. facilitated an open-call to Program Coordinators of campushosted Institute sessions for recruitment in this national study. Data were collected at nine national sessions and 38 universities that vary in terms of size, control, admissions selectivity, 
and faculty research output. A total of $n=2,405$ participants across 47 Institute sessions completed the initial pre-test. After three more phases of data collection over the course of multiple years, a total of 134 participants had completed at least $90 \%$ of the surveys associated with all four phases. These 134 students comprise the sample we used within this research study. The sample consisted of a relatively even split of freshman, sophomore, and junior-level students, 30\% $(n=41), 28 \%(n=38), 31 \%(n=42)$, respectively, with nine senior-level students and three graduate students also included. One student's class year was unknown. With respect to gender, $67 \%$ of students were reportedly women $(n=90), 31 \%$ were men $(n=42)$, and two students identified as transgender. With regard to race, the sample primarily consisted of students who identify as White, $65 \%(\mathrm{n}=87)$. The next largest racial group identified as more than one race, $10 \%(\mathrm{n}=14)$. Asian American, African American and Latinx students comprised the rest of the sample at $9 \%(\mathrm{n}=13), 7 \%(\mathrm{n}=10)$, and 5\% $(\mathrm{n}=7)$, respectively. Two students did not indicate racial group membership, and one student identified as Other.

Survey Instrument. Phase 1 was administered in hard-copy format just prior to the beginning of the Institute. Phase 2, the post-test, was also administered on-site in hard copy form, directly after the conclusion of the sixth day of the Institute. Participants received an electronic Phase 3 follow-up survey four months after the conclusion of their Institute session. The Phase 4 survey was sent electronically to participants during the late spring of 2016. The overall survey instrument consisted of three primary components: the core leadership capacity scale items, the demographic information we reported above, and several campus involvement questions.

Core Scale Items. The core set of items used in each phase of data collection directly corresponded to the Ready, Willing, and Able model of leadership capacity development (Keating et al., 2014) used as the conceptual framework for this study. Because 5-point Likert scale responses were used in AY14 and 7-point responses were used in AY15, we transformed both response scales to a 10-point scale, allowing direct comparisons across cohort groups.

Murphy's (1992) 8-item Self-Efficacy for Leadership (SEL) scale was used to assess students' confidence in leading. A sample item from this agree-disagree scale is, "I know how to encourage good group performance." The SEL has been in use for 20 years in professional and educational environments and has undergone extensive psychometric examination (Hoyt, 2005).

Motivation to engage in leadership behaviors was measured using the Motivation to Lead (MTL) scale (Chan \& Drasgow, 2001), a 27-item measure that includes scale items for affective-identity (AI), non-calculative (NC), and social-normative ( $\mathrm{SN}$ ) motivations to lead. The AI subscale assesses the degree to which an individual feels personally drawn to leadership roles and includes items such as, "Most of the time, I prefer being a leader rather than a follower when working in a group." The NC scale concerns the degree to which a person avoids rationally calculating the individual costs and benefits of holding a leadership position and includes items such as, "I never expect to get more privileges if I agree to lead a group." The SN scale is used to determine the degree to which a person leads due to a sense of duty or responsibility to others and 
includes items such as, "People should volunteer to lead rather than wait for others to ask or vote for them." The scale has been used primarily in professional and public organizations and has alpha reliabilities ranging from a low of .65 for the NC scale to a high of .91 for the AI scale.

The Social Issues Advocacy Scale (Nilsson, Marszalek, Linnemeyer, Bahner, \& Misialek, 2011), recently designed to assess a person's motivation to publicly advocate for social issues is also included as a measure of motivation to lead, as previous research has indicated that students may assume leadership roles or engage in leadership-oriented behaviors in order to address issues that are personally important to them (Harper \& Quaye, 2007; Inkelas, 2004; Renn \& Ozaki, 2010). An example survey item is, "I plan to contact policy makers to voice my opinion on issues that affect me." Aspects of political advocacy (i.e. motivation to vote, lobby, or campaign for people or political issues) encompassed in the original scale were not included in the current study. Moreover, language within each item was also adapted for an educational environment, where phrases such as "I am professionally responsible to..." were changed to "I am personally responsible to..."

The Leader Behavior Scale (Podsakoff, Mackenzie, Moorman, \& Fetter, 1990) is a widely-used 28-item instrument that includes two sub-scales focused on transformational (TransFORM) and transactional (TransACT) leadership. A sample item for transformational behavior is, "I help other group members develop a team attitude and spirit among ourselves." A sample item for transactional leadership is, "I always give positive feedback when other group members perform well." The LBS has been in use for over 20 years as a psychometric tool in both business and education settings, with Cronbach reliabilities ranging from .71 to .89 (Yukl, 2012).

Given the need for post-industrial leaders to possess an ethical orientation (Rost, 1993), a measure of ethical leadership skill is also included. The Ethical Leadership Scale (ELS), is a 10-item measure designed to examine the degree to which participants incorporate ethical behavior into their leadership values and planned behaviors (Brown et al., 2005). An example survey item is, "I define success not just by results but also the way they are obtained."

Involvement Items. Using a seven-point likert scale, Phase 4 respondents were asked to indicate their association with a number of curricular and co-curricular involvement experiences after participating in the LeaderShape Institute. These items were: I am easily able to identify a mentor (e.g. someone who I can go to for help in becoming a better leader) on campus; I participate in one or more student organization(s) on campus; I hold one or more positions of leadership in student organization(s); I have received position-specific training for managing my student organization; I have received leadership training not associated with student organization position training; I have enrolled in one or more academic courses dedicated to leadership development; I am or have been employed on campus; I have supervised others in on-campus and/or offcampus employment positions; I perform off-campus community service (affiliated with my role as a student or not); I have received services from an on-campus career development office; I participate in semester-long group projects as part of academic 
coursework. Additionally, respondents were asked if they have studied abroad (no experience, short term, semester, year-long, multiple experiences). If multiple, they were asked to provide how many times they studied abroad.

Analytic Framework. Given the exploratory nature of our first research question, regarding the examination of the shape of developmental trajectories of students, we created scale means on the relevant measures of leadership development and charted results over time. Using such a visual method allows for drawing initial conclusions and building more advanced and rigorous research questions based on our initial findings. In addition to such initial comparisons within the overall sample, we also examined differences in student trajectories when controlling for a host of campus-based experiences previously associated with student leadership development. To accomplish this end, we first created "change over time" scores for each student by subtracting their leadership scores within each scale collected during the third phase of collection (i.e. three to four months after Institute participation) from their scores collected during the fourth phase (i.e. one to two years after Institute participation). We then conducted a multiple regression analysis for each leadership scale, which allowed us to focus on the influence of any particular campus involvement effect while controlling for all others.

Methodological Limitations. Perhaps the most significant limitation to our study was the nature of our collected sample, especially regarding its genesis and size. All participants were students who had participated in a LeaderShape Institute on their campus or as part of a national session, and therefore our design cannot in any way be regarded as an experimental or quasiexperimental. Our conclusions should therefore be limited to the theoretical group of students who are inclined to participate in weeklong co-curricular leadership programs. It is arguable that few practical differences may exist between this population and those students who participate in other leadership learning interventions. Still, our findings should inform our understanding of the general population of postsecondary leadership program participants only with hesitancy. Secondarily, with less than 150 students in our sample and several correlated variables of interest to explore, a more powerful statistical method than multiple regression (e.g. growth curve modeling) was not justified given the lack of statistical power necessary for such analysis. While enough power exists for regression analyses, this limitation eliminated the possibility of modeling intra-individual growth curves using more than two data points (i.e. the third and fourth waves of data collection). The result was our subsequent inability to rigorously investigate the longitudinal effects of the LeaderShape Institute in particular. Rather, our results should be interpreted as less about the Institute and more about the long-term shape of the trajectory of students who have already participated in an Institute.

\section{Results}

We first report the means and standard deviations for each scale mean calculated for each phase of data collection, which can be found in Table 1. The shape of trends in numerical data can often be discerned more easily when displayed graphically. Therefore, the leadership skillrelated scale scales by data collection phase can be found in Figure 2, while the motivation to lead-related scores and the leader self-efficacy score can be found in Figures 3 and 4, respectively. In general, scale scores showed a non-linear shape to their trajectory, with an increase seen immediately after participating in the LeaderShape Institute, a decrease within the 
next three months, and a rebound, often to the high point of prior measurement, when assessed one or two years after the measurement process began.

Table 1. Leadership scale means by data collection phase

\begin{tabular}{l|llll} 
& Phase 1 & Phase 2 & Phase 3 & Phase 4 \\
& M (SD) & M (SD) & M (SD) & M (SD) \\
\hline TransFORM & $7.51(0.80)$ & $8.36(0.80)$ & $7.80(1.00)$ & $8.37(0.78)$ \\
TransACT & $8.14(1.13)$ & $8.73(1.15)$ & $8.12(1.46)$ & $8.61(1.07)$ \\
ELS & $7.99(0.87)$ & $8.68(0.82)$ & $8.45(0.97)$ & $8.64(0.85)$ \\
MTL-AI & $6.77(1.51)$ & $6.85(1.60)$ & $6.38(1.64)$ & $7.06(1.13)$ \\
MTL-NC & $7.43(1.29)$ & $8.33(1.34)$ & $7.17(1.66)$ & $7.99(1.21)$ \\
MTL-SN & $6.85(1.15)$ & $6.88(1.35)$ & $6.42(1.10)$ & $7.12(0.92)$ \\
SIAS & $6.96(1.18)$ & $8.01(1.15)$ & $7.52(1.17)$ & $7.97(1.25)$ \\
SEL & $7.47(1.22)$ & $8.38(1.04)$ & $7.45(1.78)$ & $8.39(0.97)$ \\
\hline
\end{tabular}

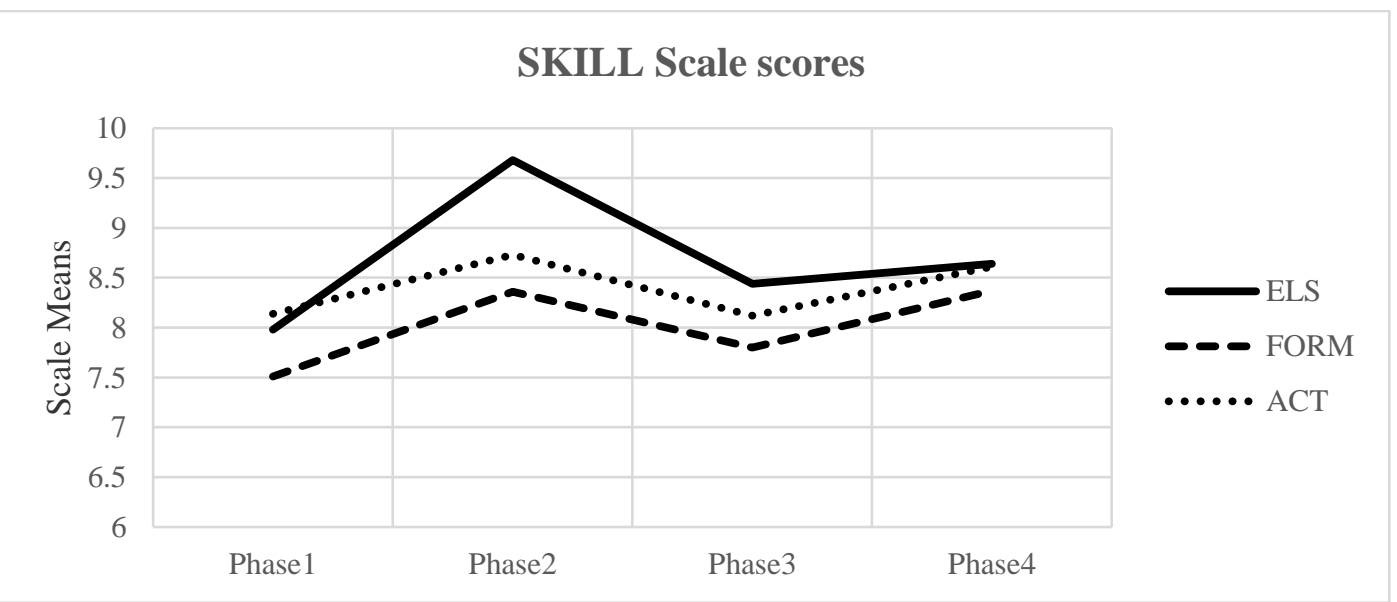

Figure 2. Leadership skill-related scores by data collection phase

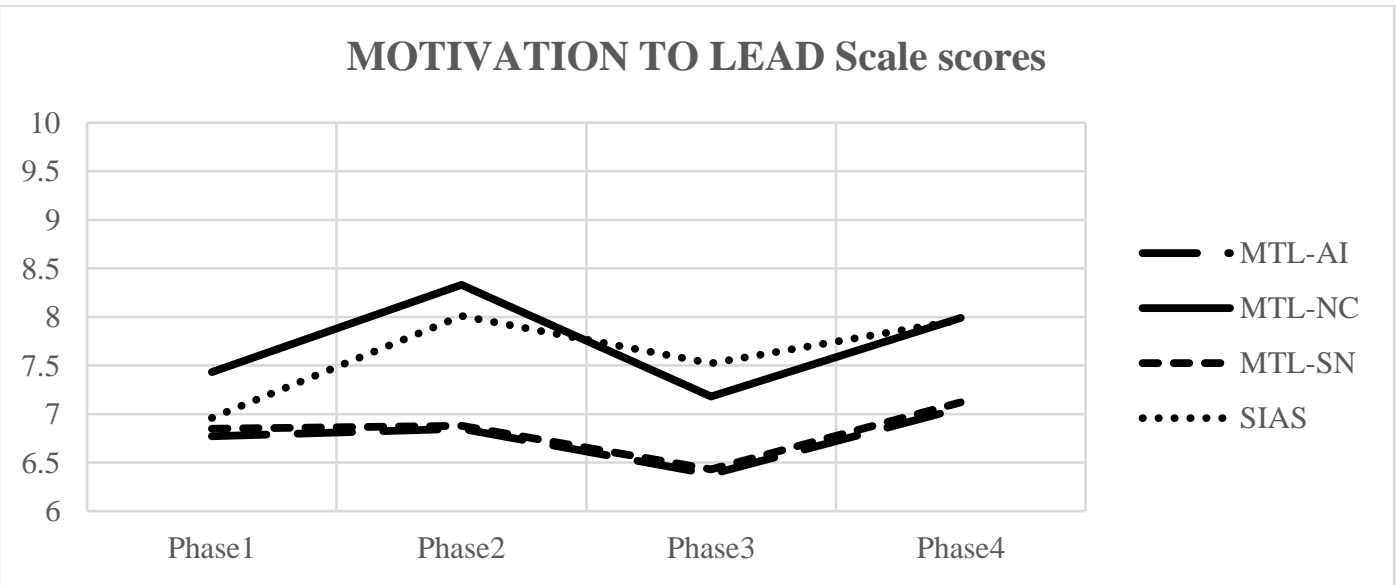

Figure 3. Motivation to lead-related scores by data collection phase. 


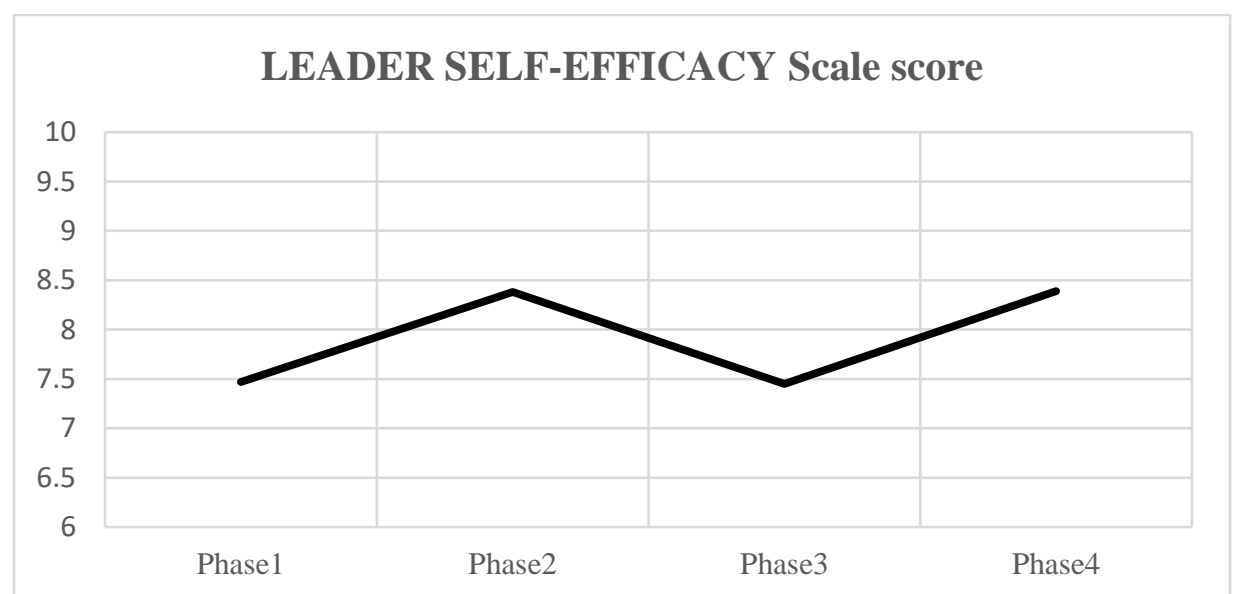

Figure 4. Leader self-efficacy scores by data collection phase.

To determine the degree to which campus-based formal and informal experiences were associated with longitudinal growth in students' leadership capacity, we conducted a series of multiple regression calculations, entering in the change in each leadership outcome score from Phase 3 (lagged post-test) to Phase 4 (follow-up one or two years later) as the dependent variable, with students' gender and racial identity, as well as their reported degree of various campus experiences, as independent variables. A summary of these analyses can be found in Table 2, which displays the total amount of variation predicted within each model (adjusted for the number of variables within each model), and each statistically significant campus involvement variable predicting the relevant change in outcome $(p<.05)$. Overall, most of the models did not predict any meaningful changes in the specific leadership outcome being measured, with all variables together predicting, in all cases but one, less than $5 \%$ of the total variance in leadership capacity. Moreover, other than students' racial identity and their participation in classroom-based group projects, no other single campus involvement variable emerged as a longitudinal predictor of leadership capacity growth.

Table 2. Campus involvement experiences longitudinally significant findings.

\begin{tabular}{l|lll} 
Outcome & $\begin{array}{l}\text { Adjusted } \mathrm{R}^{2} \\
\text { Predicted }\end{array}$ & Involvement Type & $p$ \\
\hline TransFORM & -.01 & Classroom Group Projects & .03 \\
TransACT & -.02 & & \\
ELS & -.02 & Classroom Group Projects & .03 \\
MTL-AI & .10 & Racial Identity & .001 \\
MTL-NC & -.05 & & \\
MTL-SN & .03 & Classroom Group Projects & .05 \\
SIAS & .03 & & \\
SEL & .02 & Racial Identity & .04 \\
\hline
\end{tabular}




\section{Discussion}

This study was designed to investigate the degree to which students' trajectory of leadership capacity development changes over time after participating in a formal leadership development program, as well as how their trajectories might be affected by involvement in other campus-based learning interventions that occurred after such participation. Our results show a distinct non-linear path to many students' developmental trajectories, which supports past research that also fail to show a straight line of development from prior to participation to long afterwards (Day \& Sin, 2011; Rosch et al., 2017). A typical pattern for students who participate in a formal program indicates a low pre-test score with an inflated post-test score that tapers over time to the level of pre-test assessment within a few months. However, scores climb again, often to the level seen within an immediate post-test, a year or two later. Our results suggested this trajectory pattern emerged across all three areas of leadership capacity measured transformational and transactional leadership skill, leader self-efficacy, and each aspect of motivation to lead. In addition, students' skill-related scores outstrip their leader self-efficacy and motivation to lead score across all phases of data collection.

The segment of our research focused on how other campus-based factors previously associated with student leadership development can effect such growth indicated a general lack of statistically significant findings. Substantial involvement in classroom-based academic group projects was associated with transformational and ethical leadership skill development, while no other campus factor arose as significant in affecting the long-term trajectory of students' leadership capacity. Our results also suggested students' racial identity emerged as the only variable we examined associated with motivational or self-efficacy factors (where students of color reported less growth over time) - which supports a long line of past studies that continue to show the relevance of racial identity in shaping student leadership development (Arminio et al., 2000; Collins et al., 2017; Dugan, Kodama, \& Gebhardt, 2012; Rosch et al., 2017).

Implications. The results of this study represent an important, yet limited, contribution to our understanding of the unfolding process of individual student leadership development. Few studies that focus on the effects of leadership educational initiatives follow students over the course of years; thus, our research contributes an initial indication of how non-linear the process of student leadership development may be. Students' lives, like many professionals, are filled with unexpected challenges, felt successes, and stresses to their development that can positively or negatively affect their growth. While based on a limited sample, these findings highlight the degree to which programmatic initiatives may not result in sustainable gains in leadership capacity. Moreover, the results suggest how incomplete the picture of impact of program participation is for students when data is only collected prior to and immediately after the program.

Another potential implication of this study is the degree to which differences emerged in students' reporting of their leadership skills, leader self-efficacy, and motivation to lead. At each stage of data collection, students reported having a greater capacity of leadership skill, while their reported levels of motivation to lead lagged behind even their leader self-efficacy. Many formal programs of postsecondary leadership development focus on skills to the detriment of self-efficacy and motivation (Dugan, 2011). The study provides evidence suggesting that 
students may not develop these types of capacity based on participating in more informal campus-based factors (e.g. student organizations, community service, classroom group projects), either.

Our study also provides a counterpoint to past research that indicates the degree to which formal program participation is associated with elevated leadership capacity (Cress, Astin, Zimmerman-Oster, \& Burkhardt, 2001; Dugan, 2013; Dugan \& Komives, 2010). Our results suggest that a potential reason cross-sequential research has so strongly suggested a direct link between participation and elevated capacity is that students who participate already report elevated capacity compared to those who do not participate - not because of their participation, per se. While these results should be taken as preliminary, they do indicate a distinct need for more longitudinal research in teasing out the long-term effects of participation in leadership programs on the goals of such programs.

Lastly, the emergence of race as significant to affective identity motivation to lead (MTLAI) and leadership self-efficacy (SEL) is noteworthy. Both of these measures relate to students' internal beliefs about whether they consider themselves to be "natural" leaders, and the extent to which they anticipate that their leadership efforts will be successful. Previous research has shown that for students of color, the leader label may not resonate with them, despite leadershiporiented behaviors displayed in practice (Arminio et. al, 2000). Moreover, prevailing conceptualizations of leaders as people and leadership as a process are grounded in assumptions about how identity (e.g. race, gender) affects leadership (Guthrie, Jones, Osteen, \& Hu, 2013; Ospina \& Foldy, 2009). Given that our research sample consisted only of students from Predominantly White Institutions, the less-exaggerated rates of change exhibited by students of color within the sample may be attributable to lack of sustained support in their development or by lack of visible examples of people who look like them in positions of influence and power at their institutions.

Suggestions for Leadership Educators. While preliminary, these results provide the potential indication that assessments of program effectiveness should take into consideration the need for follow-up from participants beyond a post-test in the immediate aftermath. In many instances, students' scores four months later were indistinguishable from those measured prior to participation. However, in just as many instances, they had returned to the "high" of the immediate post-test years later. Years-long assessment processes may be unrealistic for shortterm programs. However, educators might partner with other campus-based assessment officers to integrate "student leadership development" assessment into the longitudinal assessment efforts already in existence. This would have the added bonus of providing stronger statistical validity through introducing control groups (i.e. those assessed with no participation history).

In addition, educators should be encouraged to include curriculum within their programs designed to target students' leader self-efficacy and motivation to lead. While our results suggest these capacities change in similar ways to leadership skill over time, the results also indicated these more "internal" capacities lag behind more "external" skill-based capacities in students. Any professional who has served on a committee likely recognizes some of the countless organizational situations that exist where those who volunteer to lead receive more 
work, yet little support. Bolstering students' leader self-efficacy and motivation to lead may result in more prospective leaders volunteering despite these challenges.

Suggestions for Leadership Researchers. The results of this study provide a potential indication that participating in experiences designed, at least in part, to bolster student leadership capacity may not result in the uninterrupted developmental growth that past studies imply. A distinct need exists for more longitudinal analysis of students and the shape of their leadership developmental trajectories. Larger samples, and the more sophisticated statistical methods that they allow, would likely lead to results that provide a more clear indication of the shape of these trajectories, as well as how effective participation in leadership programs and co-curricular experiences are to development.

In addition, while the shape of growth within each leadership capacity area was similar in this study, our research design did not allow for examining the predictive quality of each capacity on the others. For example, is the development of leader self-efficacy required prior to developing more advanced leadership skills? Further study in this area would inform leadership educators in how to structure the timing of their curriculum.

\section{Conclusion}

This study followed a national sample of 134 students for up to two years, collected data from them at four different points in time related to their participation in a LeaderShape Institute and subsequent involvement in campus activities designed to support student leadership development. Due to the small sample size, we were only able to conduct multiple regression analyses, rather than more powerful growth curve designs. The results, which should be considered preliminary, suggest that student leadership growth is non-linear, with peaks and valleys of self-reported capacity measured over time and displayed in relatively consistent ways - such as the "honeymoon" found in scores collected in an immediate post-test after program participation. In addition, our study of campus involvement variables that contribute to longterm leadership growth showed very little overall affects, while most involvement types demonstrated no statistical relationship to student growth over time. Students' racial identity emerged as more powerful, depending on the particular leadership capacity, than all involvement factors. These results, while limited, indicate the distinct need for more robust long-term studies focused on the impact of campus variables on student leadership development. 


\section{References}

Arminio, J. L., Carter, S., Jones, S. E., Kruger, K., Lucas, N., Washington, J., \& al, et. (2000). Leadership experiences of students of color. NASPA Journal, 37(3), 496-510.

Association of American Colleges \& Universities. (2008). College learning for the new global century: Executive summary with employer's views on learning outcomes and assessment approaches. Washington, DC.

Astin, A. W., \& Astin, H. S. (2000). Leadership reconsidered: Engaging higher education in social change. Battle Creek, MI: W.E. Kellogg Foundation.

Bass, B. M. (1998). Transformational leadership: Individual, military and educational impact. Mahwah, NJ: Erlbaum.

Brown, M. E., Treviño, L. K., \& Harrison, D. A. (2005). Ethical leadership: A social learning perspective for construct development and testing. Organizational Behavior and Human Decision Processes, 97(2), 117-134.

Burns, J. M. (1978). Leadership. New York: Harper and Row.

Buschlen, E., \& Johnson, M. (2014). The effects of an introductory leadership course on socially responsible leadership, examined by age and gender. Journal of Leadership Education2, 13(1), 31-45. http://doi.org/10.12806/V13/I1/R3.

Campbell, C. M., Smith, M., Dugan, J. P., \& Komives, S. R. (2012). Mentors and college student leadership outcomes: The importance of position and process. The Review of Higher Education, 35(4), 595-625. http://doi.org/10.1353/rhe.2012.0037.

Chan, K.-Y., \& Drasgow, F. (2001). Toward a theory of individual differences and leadership: Understanding the motivation to lead. Journal of Applied Psychology, 86(3), 481-498.

Collins, J. D., Suarez, C. E., Beatty, C. C., \& Rosch, D. M. (2017). Fostering leadership capacity among black male achievers: Findings from an identity-based leadership immersion program. Journal of Leadership Education, 16(3), 82-96. DOI: 1012806/V16/I3/R4.

Council for the Advancement of Standards in Higher Education. (2009). CAS standards for leadership programs. In L. A. Dean (Ed.), CAS professional standards for higher education (7th ed.). Washington, DC: Author.

Cress, C. M., Astin, H., Zimmerman-Oster, K., \& Burkhardt, J. C. (2001). Developmental outcomes of college students' involvement in leadership activities. Journal of College Student Development, 42(1), 15-27. 
Day, D. V., \& Sin, H.-P. (2011). Longitudinal tests of an integrative model of leader development: Charting and understanding developmental trajectories. The Leadership Quarterly, 22(3), 545-560. http://doi.org/10.1016/j.leaqua.2011.04.011.

Day, D. V. (2001). Leadership development: A review in context. Leadership Quarterly, 11(4), $581-613$.

Dugan, J. P. (2008). Group involvement experiences in college: Identifying a thematic taxonomy. Graduate School. University of Maryland, College Park, College Park, MD.

Dugan, J. P. (2011). Pervasive myths in leadership development: Unpacking constraints on leadership learning. Journal of Leadership Studies, 5(2), 79-84. http://doi.org/10.1002/jls.20223.

Dugan, J. P. (2013). Patterns in group involvement experiences during college: Identifying a taxonomy. Journal of College Student Development, 54(3), 229-246. http://doi.org/10.1353/csd.2013.0028.

Dugan, J. P., Bohle, C. W., Gebhardt, M., Hofert, M., Wilk, E., \& Cooney, M. (2011). Influences of leadership program participation on students' capacities for socially responsible leadership. Journal of Student Affairs Research and Practice, 48(1), 65-84. http://doi.org/10.2202/1949-6605.6206.

Dugan, J. P., Kodama, C., Correia, B., \& Howes, S. (2013). MSL insight report: Leadership program delivery. College Park, MD.

Dugan, J. P., Kodama, C. M., \& Gebhardt, M. C. (2012). Race and leadership development among college students: The additive value of collective racial esteem. Journal of Diversity in Higher Education, 5(3), 174-189. http://doi.org/10.1037/a0029133.

Dugan, J. P., \& Komives, S. R. (2007). Developing leadership capacity in college students: Findings from a national study. A report from the Multi-Institutional Study of Leadership. College Park, MD: National Clearinghouse for Leadership Programs.

Dugan, J. P., \& Komives, S. R. (2010). Influences on college students' capacities for socially responsible leadership. Journal of College Student Development, 51(5), 525-549.

Gurin, P., Dey, E. L., Hurtado, S., \& Gurin, G. (2002). Diversity and higher education: Theory and impact on educational outcomes. Harvard Educational Review, 72(3), 330-366.

Guthrie, K. L., Jones, T. B., Osteen, L., \& Hu, S. (2013). Cultivating leader identity and capacity in students from diverse backgrounds: ASHE Higher Education Report. (K. Ward \& L. Wolf-Wendel, Eds.) (39th, 4th ed.). New York, NY: John Wiley \& Sons. 
Hannah, S. T., \& Avolio, B. J. (2010). Ready or not: How do we accelerate the developmental readiness of leaders? Journal of Organizational Behavior, 31(8), 1181-1187. http://doi.org/10.1002/job.675.

Hannah, S. T., Avolio, B. J., Luthans, F., \& Harms, P. D. (2008). Leadership efficacy: Review and future directions. The Leadership Quarterly, 19(6), 669-692. Retrieved from http://www.sciencedirect.com/science/article/pii/S1048984308001276.

Harper, S. R., \& Quaye, S. J. (2007). Student organizations as venues for Black identity expression and development among African American male student leaders. Journal of College Student Development, 48(2), 106-128.

Howard, G. S., \& Dailey, P. R. (1979). Response-shift bias: A source of contamination of selfreport measures. Journal of Applied Psychology, 64(2), 144-150.

Hoyt, C. L. (2005). The role of leadership efficacy and stereotype activation in women's identification with leadership. Journal of Leadership and Organizational Studies, 11(4), $2-14$.

Hurtado, S. (2007). Linking diversity with the educational and civic mssions of higher education. The Review of Higher Education, 30(2), 185-196. http://doi.org/10.1353/rhe.2006.0070.

Inkelas, K. K. (2004). Does participation in ethnic cocurricular activities facilitate a sense of ethnic awareness asian pacific american undergraduates. Journal of College Student Development, 45(3), 285-302.

Keating, K., Rosch, D. M., \& Burgoon, L. (2014). Developmental readiness for leadership: The differential effects of leadership courses on creating "ready, willing, and able" leaders. Journal of Leadership Education, 13(3), 1-16. http://doi.org/1012806/V13/I3/R1.

Komives, S. R., Dugan, J. P., Owen, J. E., Slack, C., \& Wagner, W. (2011). The handbook for student leadership development. San Francisco: Jossey-Bass.

Murphy, S. E. (1992). The contribution of leadership experience and self-efficacy to group performance under evaluation apprehension (Unpublished doctoral dissertation). Seattle, WA: University of Washington.

National Association of Colleges and Employers. (2013). Job outlook 2013. Bethlehem, PA: National Association of Colleges and Employers.

Nilsson, J. E., Marszalek, J. M., Linnemeyer, R. M., Bahner, a. D., \& Misialek, L. H. (2011). Development and Assessment of the Social Issues Advocacy Scale. Educational and Psychological Measurement, 71(1), 258-275. http://doi.org/10.1177/0013164410391581.

Northouse, P. G. (2015). Leadership: Theory and practice (7th ed.). Thousand Oaks, CA. 
Ospina, S., \& Foldy, E. (2009). A critical review of race and ethnicity in the leadership literature: Surfacing context, power and the collective dimensions of leadership. Leadership Quarterly, 20(6), 876-896. http://doi.org/10.1016/j.leaqua.2009.09.005.

Owen, J. (2012). Examining the design and delivery of collegiate student leadership development programs: Findings from the Multi-Institutional Study of Leadership (MSL-IS), a national report. Washington, DC: Council for the Advancement of Standards in Higher Education.

Pearson, R. W. (2009). Statistical persuasion: How to collect, analyze, and present data... accurately, honestly, and persuasively. Thousand Oaks, CA: SAGE Publications.

Podsakoff, P. M., Mackenzie, S. B., Moorman, R. H., \& Fetter, R. (1990). Transformational leader behaviors and thier effects on followers' trust in leader, satistfaction, and organizational citizenship behaviors. Leadership Quarterly, 1(2), 107-142.

Posner, B. Z. (2009). A longitudinal study examining changes in students leadership behavior. Journal of College Student Development, 50(5), 551-563.

Renn, K. A., \& Ozaki, C. C. (2010). Psychosocial and leadership identities among leaders of identity-based campus organizations. Journal of Diversity in Higher Education, 3(1), 1426. http://doi.org/10.1037/a0018564.

Rosch, D. M. (2015). Effects of classroom-based team experiences on undergraduate student leadership development: When practice does not make perfect. Journal of Leadership Education, 14(3), 104-118. DOI: 1012806/V14/I3/R7.

Rosch, D. M., \& Kuzel, M. L. (2010). What do we mean when we talk about leadership? About Campus, 15(5), 29-30.

Rosch, D. M., Ogolsky, B., \& Stephens, C. M. (2017). Trajectories of student leadership development through training: An analysis by gender, race, and prior exposure. Journal of College Student Development, 56(8), 1184-1200. Retrieved from https://doi.org/10.1353/csd.2017.0093

Rosch, D. M., \& Schwartz, L. M. (2009). Potential issues and pitfalls in outcomes assessment in leadership education. Journal of Leadership Education, 8(1), 177-194.

Rosch, D. M., \& Stephens, C. M. (2017). Campus involvement as a predictor for durable leadership development in conjunction with leadership program participation. Journal of College Student Development2, 58(7), 1107-1112. http://doi.org/10.1353/csd.2017.0087.

Rosch, D. M., Stephens, C. M., \& Collins, J. D. (2015). The LeaderShape Institute: Developmental gains in student leadership capacity. Champaign, IL: LeaderShape, Inc. 
Rosch, D. M., Stephens, C. M., \& Collins, J. D. (2016). Lessons that Last: LeaderShape-related Gains in Student Leadership Capacity over Time. Journal of Leadership Education, 15(1), 44-59.

Rost, J. C. (1993). Leadership for the twenty-first century. Westport, CT: Greenwood Publishing Group.

Seifert, T. A., Bowman, N. A., Wolniak, G. C., Rockenbach, A. N., \& Mayhew, M. J. (2017). Ten Challenges and Recommendations for Advancing Research on the Effects of College on Students. AERA Open, 3(2), 2332858417701683. http://doi.org/10.1177/2332858417701683.

Soria, K., Nobbe, J., \& Fink, A. (2013). Examining the intersections between undergraduates' engagement in community service and development of socially responsible leadership. Journal of Leadership Education, 12(1), 117-139.

Steinberg, L., \& Morris, A. S. (2001). Adolescent development. Annual Review of Psychology, 52(1), 83-110. http://doi.org/10.1146/annurev.psych.52.1.83.

Yukl, G. (2012). Leadership in organizations (8th ed.). New York: Pearson.

\section{Author Biographies}

David M. Rosch, dmrosch@illinois.edu, is an Associate Professor in the Agricultural Education Program at the University of Illinois at Urbana-Champaign, where his teaching and research is focused on the leadership development of emerging adults.

Jasmine D. Collins, jdcolli2@illinois.edu, is an Assistant Professor in the Agricultural Education Program at the University of Illinois at Urbana-Champaign. Her work situates the study of college student leadership development and identity within broader contexts of social inequality, structural racism, and campus racial climate. 